\title{
DIFERENÇAS NO COMPORTAMENTO SEXUAL, CONHECIMENTO SOBRE HPV E VACINA EM ESTUDANTES DO SEXO FEMININO E MASCULINO DE UMA INSTITUIÇÃO PÚBLICA DE ENSINO SUPERIOR
}

\section{Marília Biselli Monteiro*, Sophie F. M. Derchain, Amanda C. Ferracini e Luis Otávio Sarian.}

\section{Resumo}

Foram aplicados, em 2017, 492 questionários a estudantes do $1^{\circ}$ e $4^{\circ}$ ano dos cursos de medicina, farmácia, enfermagem, fonoaudiologia e educação física da UNICAMP. O objetivo era avaliar a diferença no conhecimento sobre o HPV e sua vacina, além da imunização prévia contra o HPV, quando comparados os cursos, o gênero, o ano de gradução e os antecedentes sexuais dos estudantes. O conhecimento sobre as consequências da infecção pelo HPV foi baixo e a taxa de vacinação foi de apenas $26 \%$ nas mulheres e $8 \%$ nos homens. Apenas $56 \%$ das mulheres referiram uso de condom contra $96 \%$ dos homens. O ingresso na universidade parece um momento oportuno para estimular o conhecimento sobre o HPV e a vacinação dos estudantes.

\section{Palavras-chave:}

HPV, vacina, ensino superior

\section{Introdução}

Com o objetivo de avaliar as diferenças no comportamento sexual, conhecimento e vacinação contra o HPV entre estudantes do sexo feminino e masculino dos cursos de medicina, farmácia, enfermagem, fonoaudiologia e educação física, foi aplicado um questionário com 79 para 492 estudantes (202 homens e 290 mulheres) cursando o $1^{\circ}$ e $04^{\circ}$ ano destes cursos e analisadas as respostas fornecidas.

\section{Resultados e Discussão}

Um total de $47 \%$ das mulheres do $1^{\circ}$ ano e $13 \%$ do $4^{\circ}$ ano referiram não ter iniciado atividade sexual vs $11 \%$ dos homens do $1^{\circ}$ e $4^{\circ}$ ano $(p<0,001)$. O uso do condom foi menor entre as mulheres (59\%) do que entre os homens $(96 \%) \quad(p<0,001)$. Entre as mulheres, $90 \%$ referiram ter consultado o ginecologista vs $26 \%$ dos homens, o urologista ( $p<0,001)$ (fig.1).

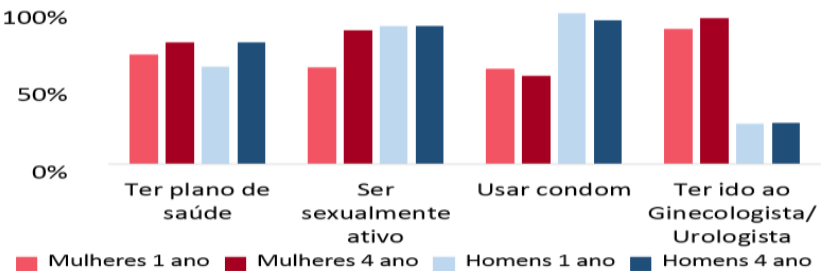

Fig.1. Antecedentes sexuais por ano de graduação/gênero

O conhecimento sobre HPV foi maior entre as mulheres $(p<0,05)$. Mais de $83 \%$ das mulheres e $66 \%$ dos homens sabiam que o HPV pode causar câncer de colo de útero $(p<0,001)$. Menos de $30 \%$ dos estudantes sabiam que 0 HPV pode causar câncer de vulva/vagina/orofaringe/ pênis $(p>0,05)$ e $48 \%$ das mulheres e $38 \%$ dos homens sabiam que pode causar verrugas nestes locais $(p<0,05)$. Quando comparado o $1^{\circ} \mathrm{com} 04^{\circ}$ ano houve um aumento no conhecimento referente à transmissão sexual do $\operatorname{HPV}(p<0,05)$, maior incidência de 15 a 25 anos $(p<0,05)$ e possível ausência de sintomas $(p<0,001)$, em ambos os sexos. $O$ conhecimento dos alunos aumentou progressivamente comparando educação física, enfermagem/fonoaudiologia, farmácia e medicina (ptrend<0,001) (fig. 2 A e B). Apenas 26\% das mulheres e $8 \%$ dos homens tomaram a vacina contra HPV $(p<0,001)$, sem relação com ter plano de saúde.

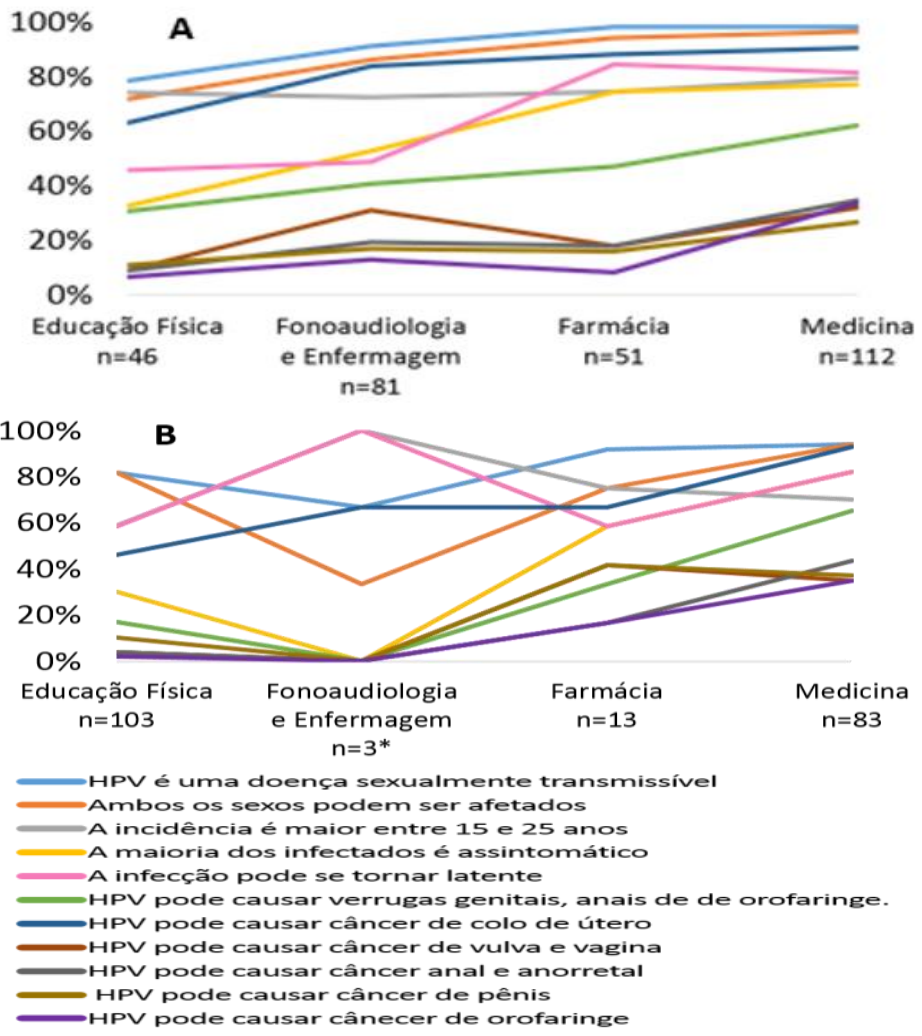

Fig.2: Conhecimento sobre o HPV entre os diferentes cursos entre A) as mulheres e B) os homens.

\section{Conclusões}

O conhecimento das mulheres referente ao HPV foi maior; já o uso de condom foi mais referido por homens. Quase metade das mulheres ingressaram na universidade sem ter iniciado atividade sexual e a taxa de estudantes vacinados foi muito baixa. $O$ ingresso na universidade parece um momento oportuno para estimular o conhecimento sobre o HPV e a vacinação dos estudantes.

\section{Agradecimentos}

Projeto financiado pela FAPESP (2017/03323-6).

Balla BC, Terebessy A, Tóth Eetal. Young Hungarian Students' Knowledge about HPVand Their Attitude Toward HPV Vaccination. Vaccines(Basel). 2016;5(1) 